BMJ Open

Sport \&

Exercise

Medicine

\title{
Descriptive analysis of objectively assessed physical activity among talented soccer players: a study of three Norwegian professional football clubs
}

\author{
Stig Arve Sæther, Nils Petter Aspvik
}

To cite: Sæther SA, Aspvik NP. Descriptive analysis of objectively assessed physical activity among talented soccer players: a study of three Norwegian professional football clubs. BMJ Open Sport Exerc Med 2017;2: e000178. doi:10.1136/ bmjsem-2016-000178

- Prepublication history and additional material is available. To view please visit the journal (http://dx.doi.org/ 10.1136/bmjsem-2016000178).

Accepted 7 December 2016

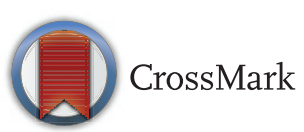

Department of Sociology and Political Science, Norwegian University of Science and Technology, Trondheim, Norway

Correspondence to Assistant Professor Stig Arve Sæther; stigarve@ntnu.no

\section{ABSTRACT}

Background: Talented football players are expected to overcome large training and match loads, indicating a high weekly level of physical activity (PA).

Aims: With the use of accelerometers, the aim of this study was to objectively describe the players' total time spent in moderate-to-vigorous PA (MVPA), vigorous PA (VPA) and very vigorous PA (VVPA) per day in 1 week. Since high-intensity PA has been highlighted as important in terms of overall PA load, we also included 2 and 4 min bouts of VPA.

Methods: Data were collected in three junior teams in professional football clubs in March (club 1: 2014 , club 2: 2012 and club 3: 2011). A one-way analysis of variance was applied to analyse differences between the three respective clubs.

Results: The players averaged 77.2-86.2 min in MVPA, 14.9-18.5 min in VPA and 1.0-3.1 in VVPA per day. While there were no differences in total time spent in MVPA and VPA per day, VVPA was significantly higher in club $1(p<0.01)$ compared with clubs 2 and 3. Moreover, when using the VPA bouts, club 3 $(p<0.01)$ achieved significantly more time in this intensity compared with clubs 1 and 2 .

Conclusion: This study acknowledges the importance of including both club-related and non-club-related PA when analysing talented football players' PA level. We suggest that future studies examining players' PA with accelerometers should emphasise time spent in highintensity PA and how this is associated with physical overload, psychological burnout and risk of injury.

\section{INTRODUCTION}

Talented football players are naturally expected to conduct large amounts of training load, since the relationship between amount of training and skills has been highlighted. ${ }^{1}$ A serious challenge for the most talented players is that they are early given opportunities of new training and match arenas outside their natural age level. Being a talented player, they are often given the opportunity to train and compete on different teams, including a higher level team within their club, a

\section{What are the new findings?}

- The players averaged $77.2-86.2 \mathrm{~min}$ in moderate-to-vigorous physical activity (MVPA), 14.9-18.5 min in vigorous physical activity (VPA) and 1.0-3.1 in very vigorous physical activity (VVPA) per day.

- There were no differences in total time spent in MVPA and VPA per day between the three studied clubs

- VVPA was significantly higher in club 1 $(p<0.004)$ compared with clubs 2 and 3.

- When using 2 and 4 min VPA bouts, club 3 $(p<0.01)$ achieved significantly more time in this intensity compared with clubs 1 and 2 .

regional team or a national team, resulting in high total load. ${ }^{2}$ This could indicate more matches and participating in fewer training sessions during a week. ${ }^{3}$ Young players' physical activity (PA) level could increase compared with players not identified as talented, since the intensity during a match is higher than in training sessions. ${ }^{4}$

As the transition from junior to senior sport is a key point in the young practitioners' career, this transition is often described as challenging, as it also coincides with important changes in life in general. ${ }^{56}$ One knows that poor coordination between sport and education is among the most common reasons for dropping out of sports. ${ }^{5}$ It can also cause problems, stress and inner conflicts in the individual athlete. ${ }^{7}$ Still, others have pointed out that education and sports have conflicting demands and thus stand in a competitive relationship above athletes who want to be the best. $^{8} 9$ Knowledge of the players' overall situation in terms of talent development is essential to reduce their risk of physical overload, ${ }^{10}$ psychological burnout ${ }^{11}$ and risk of injury. ${ }^{12}$ Monitoring talented players' PA, including activity both directed and not directed by their club, should 
Table 1 Average physical activity level during 1 week: minutes in intensity zones and one-way ANOVA between the clubs

\section{Condition}

Club 1 (95\% Cl)

( $n=24$ players)
Club 2 (95\% Cl)

( $n=18$ players)
Club 3 (95\% Cl)

( $n=16$ players)
ANOVA

p

\begin{tabular}{|c|c|c|c|c|}
\hline \multicolumn{5}{|c|}{ Freedson intensity zones } \\
\hline MVPA & $83.9(75.4$ to 92,4$)$ & 86.2 (77.6 to 94.8$)$ & 77.2 (63.9 to 90.5$)$ & 0.432 \\
\hline VPA & 18.5 (14.8 to 22.2$)$ & $18.2(16.0$ to 21.4$)$ & 14.9 (11.3 to 18.5$)$ & 0.240 \\
\hline VVPA & 3.1 (1.9 to 4.3$)$ & $1.6(1.1$ to 2.1$)$ & $1.0(0.6$ to 1.5$)$ & $\mathrm{p}<0.01$ \\
\hline \multicolumn{5}{|l|}{ Bouts } \\
\hline \multicolumn{5}{|c|}{2 min bouts in VPA per day } \\
\hline Frequencies & 0.8 (0.5 to 1.2$)$ & 0.7 (0.3 to 1.0$)$ & $2.9(2.1$ to 3.6$)$ & $p<0.01$ \\
\hline Total minutes & 3.2 (2.0 to 4.3$)$ & 2.2 (1.1 to 3.3$)$ & 10.9 (7.6 to 14.2$)$ & $\mathrm{p}<0.01$ \\
\hline Total counts & 3846.4 (3227.8 to 4310.9$)$ & 2578.5 (1721.3 to 3435.7$)$ & 4992.8 (4132.3 to 5853.3$)$ & $\mathrm{p}<0.01$ \\
\hline \multicolumn{5}{|c|}{4 min bouts in VPA per day } \\
\hline Frequencies & 0.2 (0.2 to 0.3$)$ & 0.1 (0.1 to 0.2$)$ & 1.2 (0.7 to 1.6$)$ & $\mathrm{p}<0.01$ \\
\hline Total minutes & 1.6 (1.0 to 2.3$)$ & $0.8(0.3$ to 1.4$)$ & 6.8 (4.2 to 9.4$)$ & $\mathrm{p}<0.01$ \\
\hline Total counts & 2080.5 (1398.0 to 2767.1$)$ & 707.0 (299.1 to 1114.9$)$ & 3763.6 (2843.5 to 4683.8 ) & $\mathrm{p}<0.01$ \\
\hline
\end{tabular}

Axis 1 counts/min=total counts per minute.

ANOVA, analysis of variance; MVPA, moderate-to-vigorous physical activity; VPA, vigorous physical activity; VVPA, very vigorous physical activity.

therefore be an important part of talent development. In that case, one acknowledges that it is reasonable that a talented player is also being active (ie, selforganised exercise and attending physical education classes) outside club-directed trainings and competitions.

Previous research has attempted to describe a normal training week for both professional ${ }^{13}$ and youth football players. ${ }^{14} 15$ One obvious limitation of these studies is their sole focus on club-related PA load (training and match) with different approaches and measurements, including how both external ${ }^{16-18}$ and internal $^{14}$ training and match load can influence players' physiological response. There is therefore call for studies examining players' total daily PA, including both club-related and non-club related activities.

Few studies have used objective measurements to assess daily PA in talented football players. ${ }^{19}$ In a study of a similar sample of talented football players, Sæther and Aspvik ${ }^{19}$ found the objectively measured PA level among talented football players to be high throughout the season. This was, however, measured as overall PA level using counts per minute. A limitation in the counts-per-minute calculation is that it is an average measure for the day and not related to time in different intensities. Related to challenges in talent development, such as physical overload ${ }^{10}$ surveillance of talented football players' PA level is important, especially time spent in higher intensities. To the authors' knowledge, there are no published reference values for youth talented football players' time spent in higher intensities. The aim of this study was therefore to establish objectively measured reference values for Norwegian youth talented football players' PA level, more specifically players' time per day spent in moderate-to-vigorous PA (MVPA), vigorous PA (VPA) and very vigorous PA (VVPA), reporting both total minutes and minutes conceded in 2 and 4 min bouts. With regard to data generalisability, an additional aim was to report and compare PA data between three different clubs with youth elite players.

\section{EQUIPMENT AND METHODS}

\section{Sample and data collection}

Participants included 58 male elite youth football players (age $=17.5$, SD 1.12) who represented three top-level clubs in Norway. Clubs 1 and 3 were premierlevel clubs, while club 2 was a second-level club. The two premier-level clubs had, on average, five training sessions and one match per week. The second-level club had four training sessions and one match per week. Both training sessions and matches lasted for $90 \mathrm{~min}$. All teams are playing at the highest junior level in Norway. Players from all these teams have played at the top-level senior teams, but very few have professional contracts with the elite team. Informed written consent was obtained from players, parents of underage players and coaches. The study (ethics clearance) was in accordance with and approved by the Norwegian Social Science Data Services. Data were collected in March for all clubs, but in different years: 2011 for club 3, 2012 for club 2 and 2014 for club 1 . 
The average daily monitoring time was 10.5 hours for all clubs.

\section{Procedure and data analyses}

ActiGraph GT3X accelerometer (Actigraph, Pensacola, Florida, USA) was used to obtain objective assessment of PA among the talented football players. The accelerometer was firmly placed and adjusted on the players' waist by an elastic belt over the right hip. The players were instructed to wear the monitor for 7 days, from the time they got out of bed in the morning until they went to bed at night (except during showering and swimming activities). In the present study, the epoch was set with $60 \mathrm{~s}$ intervals. The accelerometer output was converted into activity counts reflecting the intensity of bodily movement, more specifically counts per minute (CPM). The higher the CPM value, the higher the intensity. More importantly, a highly significant correlation between PA recorded by the accelerometers and energy expenditure assessed by indirect calorimetry has been found. In addition, there has been a high degree of interinstrument reliability. ${ }^{20}$ However, while a high correlation $(\mathrm{r}=0.86)$ between accelerometer recordings and energy expenditure in laboratory settings has been reported, ${ }^{21}$ others have questioned whether this level of precision can be reproduced during everyday activities. ${ }^{22}$

The Actilife software V.6.11.5 (Actigraph, Pensacola, Florida, USA) was used to process the data. Non-wear time was defined as periods of 60 consecutive min of zero counts, with allowance of $2 \mathrm{~min}$ of counts greater than zero, and was excluded from the analysis. Players failing to provide our wear-time validation (WTV) data with at least 4 days of 10 hours per day were excluded from the study. After the WTV, the study sample included $14(61 \%)$ players in club 3, $18(75 \%)$ in club 2 and $24(85 \%)$ in club 1 . The variables examined in the present study were total time (minutes) spent in moderate-to-vigorous PA (MVPA >1952 CPM), vigorous physical activity $\mathrm{PA}(\mathrm{VPA}>5725 \mathrm{CPM})$ and very vigorous physical activity (VVPA $>9500 \mathrm{CPM}) .^{23}$ The amount of time spent in the different intensities was estimated by summing the total minutes per day. In addition, 2 and $4 \mathrm{~min}$ bouts (consecutive minutes) of VPA were estimated, giving frequencies of bouts, total minutes in bouts and total counts in bouts per day.

Statistical Package for the Social Sciences (PASW Statistics V.18.0) for Windows was used to analyse the data. One-way analysis of variance (ANOVA) was performed on the accelerometer scores to test for differences between the three clubs.

\section{RESULTS}

The results showed no significant differences of total time spent in MVPA $(\mathrm{p}<0.432)$ and VPA $(\mathrm{p}<0.240)$ among the three different clubs. Players' time spent in MVPA, VPA and VVPA, in average per day, is displayed in table 1.
In this study, talented youth football players averaged 77.2-86.2 $\mathrm{min}$ in MVPA, $14.9-18.5 \mathrm{~min}$ in VPA and 1.0-3.1 in VVPA each day. Players in club 1 had a significantly higher amount of time spent in VVPA compared with clubs 2 and $3(\mathrm{p}<0.01)$. Club 3 had a significantly higher number and amount of time spent in both 2 and 4 min bouts compared with clubs 1 and 2 $(\mathrm{p}<0.01)$.

\section{DISCUSSION}

Talented football players are expected to overcome large training and match loads, ${ }^{2}$ especially in their youth years. To be able to get an overview of the players' PA level, one has to consider both the club and the non-club organised PAs. ${ }^{4}$ Studying the PA level among talented football players over an entire week provides the opportunity of getting such an overview of the players' PA level. Earlier studies have described training amounts of youth players, indicating a large training amount. ${ }^{10}$ By using different measurements, earlier studies have described a normal training and match week within a club for both professional and youth players, ${ }^{13-15}$ but none of these have objectively described players' PA throughout the day, including both club and non-club activities.

The lack of studies using accelerometers to assess talented football players' time spent in higher intensity zones makes our results hard to compare. However, a study examining a similar sample as analysed in the present study described talented football players' overall PA level to be high. ${ }^{19}$ Moreover, they reported no significant difference in PA level between the three studied weeks during the measured season. This was, however, measured in one club only. By including three top-level junior football clubs in the present study, the authors acknowledged that similarities and differences in talented football players' PA level might be related to their clubs.

With regard to the total time per day spent in MVPA and VPA, the present study found no significant differences between the three measured clubs. However, club 1 had significantly more minutes in VVPA compared with the two other clubs. This might indicate that the highest intensities are separating the clubs with regard to PA level. Interestingly, when analysing 2 and 4 min bouts of VPA, we found a different pattern between the three clubs compared with the total time in the highest intensity (VVPA). Although club 1 had significantly more total minutes spent in VVPA compared with clubs 2 and 3, it was club 3 that clearly had the largest amount of time spent in 2 and $4 \mathrm{~min}$ bouts of VPA. Overall, the top-level clubs (clubs 1 and 3) have more time in higher intensities compared with the second-level club (club 2). Interestingly, the high intensity is carried out differently between the two toplevel clubs. The most obvious explanation for these differences is that total time and bouts are measuring different aspects of PA. However, it is also reasonable 
to assume that it reflects the clubs' way of exercising. While some clubs might have very vigorous intensities in short bouts ( $>1 \mathrm{~min}$ ), other clubs might have at least 2-4 min (continuous) in vigorous intensities.

When analysing PA, it is important to acknowledge that there are individual differences among young talented football players. ${ }^{3}{ }^{12}$ While this study is focusing on mean PA differences between clubs, it is also important to emphasise individual player's differences within the clubs. In the three clubs investigated, we did, however, find small variations with regard to players' time spent in higher intensities. More knowledge about young talented football players' daily time spent in higher intensities is important with regard to players' individual development. In addition, this knowledge might reduce young players' risk of physical overload, ${ }^{10}$ psychological burnout $^{11}$ and risk of injury. ${ }^{12}$

The results in the present study illustrate the impact different methodological approaches have when analysing PA among talented football players. First, future studies should continue to include both club and nonclub activities in understanding young talented football players' PA level. Second, both total time and bouts of time spent in different intensity zones should be included, especially time spent in the higher intensities. This will contribute to a more comprehensive description and knowledge about talented football players' PA level.

The authors recognise some limitations of the study. We used uniaxial data to analyse players' PA level. However, based on the activity characteristics of football, we would recommend future studies to use triaxial accelerometers. With regard to the study results' generalisability, the study employed a small sample size. However, since the sample was divided into three different clubs, it is reasonable to argue that the findings are not random. The authors acknowledge that PA data were assessed at only 1 week in the season (March), which might have affected the study results. However, a recent study $^{19}$ did not report seasonal differences in overall PA in youth talented football players. Since this is the first study reporting reference values of objectively measured time spent in higher intensities, there is a need for comparable studies to verify the present study data. Furthermore, it is important to acknowledge that the present study used commonly used absolute thresholds for intensity, which is not adjusted for the population sample examined (ie, physical fitness and gender).

\section{CONCLUSION}

This study highlights the importance of including both club-related and non-club-related PA when analysing talented football players' PA level. In this study, talented young football players averaged $77.2-86.2 \mathrm{~min}$ in MVPA, 14.9-18.5 min in VPA and 1.0-3.1 in VVPA per day. The results in the present study illustrate the importance of focusing on high intensity when analysing PA among talented football players. While club 1 had significantly more total time in VVPA compared with clubs 2 and 3 , club 3 had significantly more time spent in 2 and $4 \mathrm{~min}$ bouts compared with clubs 1 and 2. By analysing total time in MVPA, no significant difference was found between the three clubs investigated. We emphasise that future studies aiming to understand talented football players' PA should acknowledge both club and non-club PA and the value of including a broad range of PA data (ie, triaxial data, accelerometer data, using different intensity zones, total time and bouts).

Acknowledgements The authors highly appreciate the co-operation of all the players who volunteered their time to fill in the questionnaire.

Competing interests None declared.

Ethics approval Norwegian Social Science Data Services.

Provenance and peer review Not commissioned; externally peer reviewed.

Open Access This is an Open Access article distributed in accordance with the Creative Commons Attribution Non Commercial (CC BY-NC 4.0) license, which permits others to distribute, remix, adapt, build upon this work noncommercially, and license their derivative works on different terms, provided the original work is properly cited and the use is non-commercial. See: http:// creativecommons.org/licenses/by-nc/4.0/

(c) Article author(s) (or their employer(s) unless otherwise stated in the text of the article) 2017. All rights reserved. No commercial use is permitted unless otherwise expressly granted.

\section{REFERENCES}

1. Ericsson KA, Krampe RT, Tesch-Römer C. The role of deliberate practice in the acquisition of expert performance. Psychol Rev 1993; 100:363-406.

2. Malina RM, Peña Reyes ME, Eisenmann JC, et al. Height, mass and skeletal maturity of elite Portuguese soccer players aged 11-16 years. J Sports Sci 2000;18:685-93.

3. McMillan K, Helgerud J, Grant SJ, et al. Lactate threshold responses to a season of professional British youth soccer. Br J Sports Med 2005;39:432-6.

4. Capranica L, Tessitore A, Guidetti L, et al. Heart rate and match analysis in pre-pubescent soccer players. J Sports Sci 2001:19:379-84.

5. Enoksen E. Drop-out rate and drop-out reasons among promising norwegian track and field athletes: a 25 year study. Scandinavian Sport Studies Forum 2011;2:19-43.

6. Stambulova N. The transition from junior to senior sports: a summary of six Swedish studies. In: Theodorakis Y, Goudas M, Papaioannou A, eds. Book of abstracts. Proceedings of the 12th European Congress of Sport Psychology. Halkidiki: FEPSAC, 2007:126-7.

7. Christensen MK, Sorensen JK. Sport or school? Dreams and dilemmas for talented young danish football players. Eur Phy Educ Rev 2009;15:115-33.

8. Bourke E. The dream of being a professional soccer player: Insights on career development options of young irish players. J Sport Soc Issues 2003;27:399-419.

9. McGillivray D, Mclntosh A. 'Football is my life': theorizing social practice in the Scottish professional football field. Sport Soc 2006;9:371-87.

10. Brenner JS. American Academy of Pediatrics Council on Sports Medicine and Fitness. Overuse injuries, overtraining, and burnout in child and adolescent athletes. Pediatrics 2007;119:1242-5.

11. Hill AP. Perfectionism and burnout in junior soccer players: a test of the $2 \times 2$ model of dispositional perfectionism. J Sport Exerc Psychol 2013;35:18-29.

12. Brito J, Malina RM, Seabra A, et al. Injuries in portuguese youth soccer players during training and match play. J Athl Train 2012;47:191-7. 
13. Bangsbo J, Mohr M, Krustrup P. Physical and metabolic demands of training and match-play in the elite football player. J Sports Sci 2006;24:665-74.

14. Akubat I, Patel E, Barrett S, et al. Methods of monitoring the training and match load and their relationship to changes in fitness in professional youth soccer players. J Sports Sci 2012;30:1473-80.

15. Wrigley R, Drust B, Stratton G, et al. Quantification of the typical weekly in-season training load in elite junior soccer players. J Sports Sci 2012;30:1573-80.

16. Rampinini E, Impellizzeri FM, Castagna C, et al. Factors influencing physiological responses to small-sided soccer games. J Sports Sci 2007;25:659-66.

17. Hill-Haas SV, Coutts AJ, Rowsell GJ, et al. Generic versus smallsided game training in soccer. Int J Sports Med 2009;30:636-42.

18. Brink MS, Nederhof E, Visscher C, et al. Monitoring load, recovery, and performance in young elite soccer players. J Strength Cond Res 2010;24:597-603.
19. Sæther SA, Aspvik NP. Seasonal variation in objectively assessed physical activity among young Norwegian talented soccer players: A description of daily physical activity level. J Sports Sci Med 2014:13:964-8.

20. Janz KF, Witt J, Mahoney LT. The stability of children's physical activity as measured by accelerometry and self-report. Med Sci Sports Exerc 1995;27:1326-1332.

21. Trost SG, Ward DS, Moorehead SM, et al. Validity of the computer science and applications (CSA) activity monitor in children. Med Sci Sports Exerc 1998;30:629-33.

22. Harro M, Riddoch C. Physical activity. In: Armstrong N, Mechelen W V, eds. Pedriatric Exercise and Medicine. Oxford: Oxford University Press, 2000:77-83.

23. Freedson PS, Melanson E, Sirard J. Calibration of the computer science and applications, Inc. accelerometer. Med Sci Sports Exerc 1998;30:777-81. 